\title{
An integrated multi-stage supply chain inventory model with imperfect production process
}

\author{
Soumita Kundu* and Tripti Chakrabarti
}

Department of Applied mathematics, University of Calcutta, 92 A.P.C. Road Kolkata 700009, India

\begin{tabular}{l}
\hline C H R O N I C L E \\
\hline Article history: \\
Received October 142014 \\
Received in Revised Format \\
February 102015 \\
Accepted March 292015 \\
Available online \\
April 5 2015 \\
\hline Keywords: \\
Integrated supply chain \\
Multi-buyer \\
Rework \\
Shipment
\end{tabular}

\section{A B S T R A C T}

This paper deals with an integrated multi-stage supply chain inventory model with the objective of cost minimization by synchronizing the replenishment decisions for procurement, production and delivery activities. The supply chain structure examined here consists of a single manufacturer with multi-buyer where manufacturer orders a fixed quantity of raw material from outside suppliers, processes the materials and delivers the finished products in unequal shipments to each customer. In this paper, we consider an imperfect production system, which produces defective items randomly and assumes that all defective items could be reworked. A simple algorithm is developed to obtain an optimal production policy, which minimizes the expected average total cost of the integrated production-inventory system.

\section{Introduction}

The globalization of world economy and increasing competitive markets have compelled business to improve the performance of the supply chain that can promptly respond to customer requirements and make sure the availability of the products and worldwide services to the customer. Shipment of the product in small lots decreases the inventory holding cost but raises set-up, ordering and transportation costs. Conversely, shipment in larger lots increases inventory holding cost but reduces the other costs, and scheduling interference results due to limited storage space for both the manufacturer and the buyers. Coordination of the scheduling of these stages is essential to take competitive advantages as it reduces overall supply chain cost.

A large numbers of research works have been concentrated on the buyer-vendor integrated inventory model. Goyal (1977) developed a joint economic lot-size model for single buyer and single vendor with infinite production rate. Later, Banerjee (1986) generalized the model by considering finite rate of production for the product with "lot for lot" shipment policy. The research related to integrated vendor buyer (IVB) models prior to 1989 is well reviewed in the paper of Goyal and Gupta (1989). Afterwards, Lu (1995) suggested an optimal policy in which delivery quantity to the customer is identical at each shipment. Goyal (1995) relaxed the restriction of identical shipments and considered different shipments 
policy in which successive shipments within a production batch are increasing by a constant factor. Later Hill (1997) extended this shipment policy more generally by allowing the geometric growth factor as a decision variable. Hill (1999) and Goyal and Nebebe (2000) kept researching on IVB systems to obtain the best optimal results by considering alternative policies. All the previous studies cover IVB models without considering the raw material procurement.

Some researchers developed integrated procurement-production (IPP) systems to minimize the total cost by determining the raw material procurement lot size and the manufacturing batch size without taking the buyer's ordering quantity or the inventory holding cost into consideration (Golhar \& Sarker, 1992; Jamal \& Sarker, 1993; Sarker \& Parija, 1994). Lee (2005) proposed an integrated inventory model for a single manufacturer, single-buyer supply chain problem by jointly considering IVB and IPP systems.

A new area of integrated supply chain, i.e., single vendor and multi buyer was suggested by Joglekar and Tharthare (1990) and they presented an alternate solution of the same problem proposed by Banerjee (1986). They refined Joint Economic Lot Size (JELS) by breaking set-up cost into vendors' order processing and handling cost per production run setup cost and named this approach as the Individual Responsible and Rational Decision (IRRD). They believed this approach could help the vendor and the buyers take their individual rational decisions. Viswanathan and Piplani (2001) developed a one-vendor multi-buyer supply chain model for a single item to study the advantage of synchronizing the supply chain inventories through common replenishment time periods without considering the inventory of the vendor. Hoque (2008) developed the optimal solution procedures of three models for single-vendor multi-buyer two of which transfer with equal batches and the third with unequal batches of a single product.

Previous studies related to buyer vendor coordination were focused on obtaining minimum total cost by determining raw material procurement lot size, the manufacturing batch size and buyer's ordering quantity, in which the quality-related issues of the product in manufacturing facility are not taken into consideration. However, because of deterioration or other factors, the manufacture process may produce poor quality items. These defective items are either wasted as scraps or sold at a discounted price at the end of the screening process, as many industries having no reworking facility and consequently, the industries lose a big share of profit margin.

Lee et al. (1997) dealt with the imperfect production and quality control issue in a multi-stage production system but they did not employ rework process for defective items. To reduce overall production costs, a production system may have a repair or rework facility. Hayek and Salameh (2001) obtained an optimal operating policy in a lot sizing problem under the effect of reworking of all defective items. Jamal et al. (2004) proposed a single-stage production system in which rework is done under two different operational policies to obtain the optimum batch quantity. In the first policy, the defective items are reworked within the same production cycle. In the second policy, the defective items are accumulated for a certain number of cycles before they are reworked. Giri and Chakraborty (2011) considered a singlevendor single-buyer supply chain model where the production process at the vendor is not perfectly reliable. During a production run, it may shift from an in-control state to an out-of-control state at any random time and produces some defective items. Hsu and Hsu (2012) developed an integrated vendorbuyer inventory model with imperfect product quality and inspection errors. Giri and Sharma (2014) proposed an unequal-sized shipment policy for an integrated production-inventory system under imperfect production process. They assumed that the retailer performs a screening process after getting the ordered quantity and the manufacture incurs a warranty cost.

In this paper, we have developed an integrated supply chain inventory model consists of a single manufacturer and multi-buyer, where manufacturer orders a fixed-quantity of raw material from outside supplier, processes the materials, and delivers in unequal shipments of finished products to each 
customer. We also assume that during production process, a portion of defective items is produced randomly which is reworked in each cycle after the end of a production run.

\section{Assumption and Notation}

To simplify the analysis, we make the following assumptions:

1. Demand and production rates are deterministic and constant.

2. Each buyer estimates individual demand, holding and ordering costs under various cost factors and informs the manufacturer.

3. There is no initial inventory.

4. Shortages are not allowed.

5. All defective items are considered to be repairable and are reworked.

6. No scrap is produced during normal and rework processing.

7. The transport equipment has enough capacity to transport any of the batches to a buyer; and setup and transportation times are insignificant.

We use the following notations:

$D_{R} \quad$ Demand rate of raw material (unit/year)

$D \quad$ Demand rate of finished goods (unit/year)

$D_{i} \quad$ Demand rate of finished goods for $\mathrm{i}^{\text {th }}$ buyer (unit/yr); $D=\sum_{i=1}^{k} D_{i}$

$P \quad$ Production rate per unit time (units/year)

$P_{1} \quad$ Reworking rate per unit time (units/year) $; P_{1} \geq P$

$d \quad$ Production rate of defective items per unit time (units/year)

$x \quad$ Portion of defective items produced randomly; $d=P x$

$v \quad$ Number of production run covered from one procurement of raw material

$n \quad$ Number of shipments of finished goods

$f \quad$ Conversion factor of the raw materials to finished goods; $f=D / D{ }_{R}=v Q_{M} / Q_{R}$

$Q \quad$ Size of the first shipment of finished goods from manufacturer

$Q_{i} \quad$ Size of the first shipment of finished goods to ith buyer $(i=1,2, \ldots k)$

$\lambda \quad$ Proportional increase in size of successive shipments

$Q_{M} \quad$ Quantity of finished goods manufactured per set up(units/batch)

$S_{i} \quad$ Size of the ith shipment of finished goods from manufacturer

$Q_{R} \quad$ Quantity of raw materials required in each batch; $Q_{R}=v Q_{M} / f$ (units/order)

$A_{R} \quad$ Ordering cost of raw material (\$/order)

$A_{M} \quad$ Manufacturing set up cost (\$/batch)

$A_{B i} \quad \mathrm{i}^{\text {th }}$ buyer's ordering cost (\$/order)

$C_{M} \quad$ Unit manufacturing cost (\$/unit)

$C_{o} \quad$ Raw material cost (\$/unit)

$T_{1} \quad$ Production uptime for the proposed EPQ model; $T_{1}=Q_{M} / P$ (in years)

$T_{2} \quad$ Time required for reworking of defective items; $T_{2}=x Q_{M} / P_{1}$ (in years)

$C_{I} \quad$ Rework cost (\$/unit)

$C_{T i} \quad$ Cost of transporting a batch from the manufacturer to $\mathrm{i}^{\text {th }}$ buyer

$C_{R} \quad$ Unit inventory value of raw material (\$/unit)

$C_{M P} \quad$ Unit inventory value of manufacturer's finished goods of perfect quality (\$/unit)

$C_{M D} \quad$ Unit inventory value of defective items (\$/unit)

$C_{B i} \quad$ Unit inventory value of $\mathrm{i}^{\text {th }}$ buyer's incoming inventory (\$/unit); $C_{B i}>C_{M P}>$ $C_{M D}>C_{R}$

$r \quad$ Annual capital cost per dollar invested in inventory

TC Expected total cost per year (in \$) 


\section{Model Formulation}

Here we have considered a manufacturing system, which procures raw materials from suppliers, processes them to convert to finished products. During the production time, $x$ portion of defective items is produced randomly at a rate $d$.

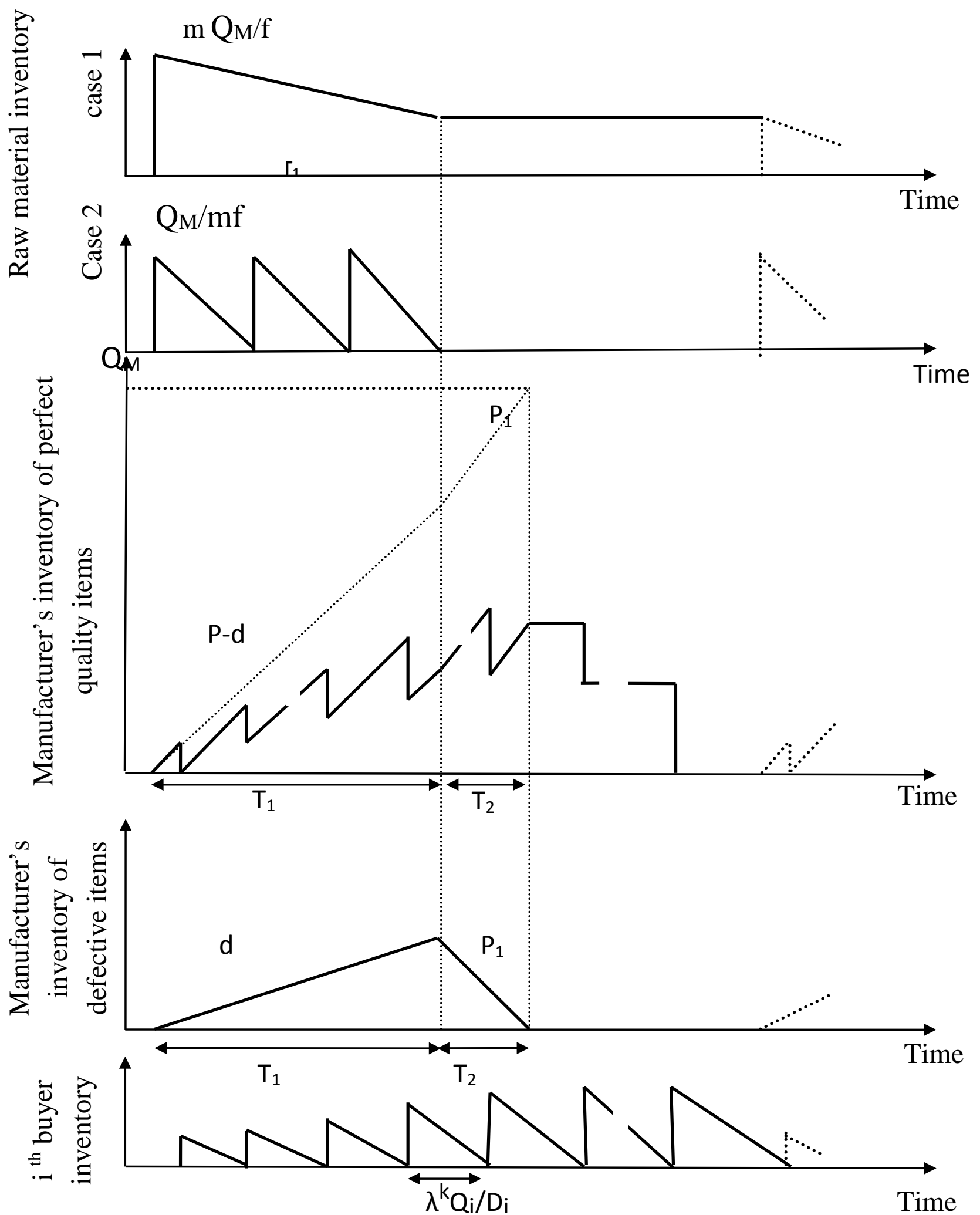

Fig. 1. Inventory of manufacture's raw material, finished items (of perfect and imperfect quality) and buyer's incoming items 
All defective items are reworked at a rate $P_{1}$ in each cycle at the end of a production run. In order to avoid shortages, we assume that the production rate $P$ has to be larger than the sum of demand rate $D$ and production rate of defective item $d$. That is: $(\mathrm{P}-\mathrm{d}-\mathrm{D})>0$ or $(1-x-D / P)>0$; where $d=P x$. The demand is met from item of perfect quality. The manufacturer delivers the entire lot $Q_{M}$ by $n$ unequal shipment of sizes $Q, \lambda Q, \ldots \lambda^{n-1} Q$ to meet the demands of all of the buyers. Since $C_{M P}<C_{B \mathrm{i}}$, the manufacture delivers a shipment only when the buyers are almost to run out of stock. When the production starts, the total stock in the system is the demand during the time to produce the first shipment and this is minimized when the first shipment is the smallest one. Therefore, we have a sequence of shipment, which increases in size and hence $\lambda \geq 1$. The first shipment from manufacturer to buyers takes place as soon as the required shipment quantity $Q$ is produced, the dispatch of the first shipment will return the manufacturer stock items of perfect quality to zero. The time to produce second shipment, $\lambda Q / \mathrm{P}(1-\mathrm{x})$ cannot be greater than the time for the demand process to consume the first shipment, $Q / D$, and this gives $\lambda \leq \mathrm{P}(1-\mathrm{x}) / \mathrm{D}$. Fig 1 shows the inventory of manufacture's raw material, manufacturer's finished items of perfect and imperfect quality and buyer's incoming items.

Different types of costs incorporated with manufacturer's and customers' are considered here for the integrated inventory model under an infinite planning horizon.

\subsection{Manufacturer's cost}

These manufacturer's costs are raw material cost and production cost.

\section{Raw material cost}

Manufacturer procures raw materials from the suppliers and converts to finished goods with a conversion factor $f$.The raw material ordering lot size, $Q_{R}$, can be represented as $Q_{R}=v Q_{M} / f=v(n+$ 1) $Q / f$, where $v$ be the number of production runs covered by a single procurement of raw materials. When $v=1$ then the raw materials required for each production run is delivered in only one shipment, which is a special case. We consider the two possible ordering situations separately: $v=\{1,2, \ldots m\}$ for Case 1 and $v=\{1,1 / 2, . .1 / m\}$ for Case 2, where $m$ is an integer.

Raw material ordering cost per year becomes $A_{R} \frac{D(\lambda-1)}{v Q\left(\lambda^{n}-1\right)}$

Raw material purchasing cost per year is $C_{o} \frac{D}{f}$

While evaluating the raw material holding cost, we consider the two possible cases independently. For case 1 , each lot size of ordered raw material will meet the demand of $m$ (say) production runs. On the other hand, for case 2 the manufacturer needs to replenish raw materials m times for every production run. The average inventory for each of the cases can be derived as (see Appendix A)

Case 1: $Q_{\text {Ravg }}=\frac{Q\left(\lambda^{n}-1\right)}{2 f(\lambda-1)}\left(\frac{D}{P}+m-1\right)$

Case 2: $Q_{\text {Ravg }}=\frac{Q\left(\lambda^{n}-1\right)}{2 f(\lambda-1)}\left(\frac{D}{m P}\right)$

Hence the raw material holding cost per year is $r C_{R} Q_{R a v g}$

\section{Production costs}

The manufacturer's production lot size is $Q_{M}$; the lot is delivered by $n$ unequal shipment of sizes $Q, \lambda Q, \ldots \lambda^{n-1} Q$ to meet the demands of all of the buyers. We assume that $Q_{i}=D_{i} Q / D, \lambda Q_{i}=$ $D_{i} \lambda Q / D, \ldots \lambda^{n-1} Q_{i}=D_{i} \lambda^{n-1} Q / D$ so that $Q=\sum_{i=1}^{k} Q_{i}$ 
Production set up cost per year is $A_{M} \frac{D(\lambda-1)}{Q\left(\lambda^{n}-1\right)}$

During production uptime the manufacturer's on-hand inventory of perfect quality items are increasing with the rate of $P-d$ and during the reworking period, increasing with the rate of $P_{1}$ while depleted by a quantity of $\lambda^{i-1} Q$ for every time interval of $\lambda^{i-1} Q / D$. Therefore, a saw-tooth pattern is built up in the manufacturer's on-hand inventory of perfect quality item during the time interval $\left[0, T_{1}+T_{2}\right]$ (see Fig 1). While during the production downtime, the manufacturer's inventory of perfect quality item is flat if no replenishment is taken place and it will be vertically dropped by a quantity of $\lambda^{i-1} Q$ at the end of every shipment to the buyers. Thus, the average inventory of perfect quality can be derived as (see Appendix B)

$$
Q_{\text {Pavg }}=\frac{Q}{2}\left[\frac{2 D}{P(1-x)}+\frac{2 \lambda\left(\lambda^{n-1}-1\right)}{\lambda^{2}-1}-\frac{\lambda^{n}-1}{\lambda-1}\left[\frac{D}{P}+D\left(\frac{x}{P}+\frac{x^{2}}{P_{1}}\right)\right]\right] .
$$

The average inventory of defective item is

$$
Q_{D a v g}=\frac{D Q\left(\lambda^{n}-1\right)}{2(\lambda-1)}\left(\frac{x}{P}+\frac{x^{2}}{P_{1}}\right)
$$

Hence the expected holding cost for manufactured items per year is

$r C_{M P} E\left[Q_{P a v g}\right]+r C_{M D} E\left[Q_{D a v g}\right]$

Expected reworking cost per year is $C_{I} D E[x]$ and manufacturing cost per year is $C_{M} D$.

Hence the expected manufacturer cost per year is

$$
\begin{aligned}
T C_{M}= & A_{R} \frac{D(\lambda-1)}{v Q\left(\lambda^{n}-1\right)}+A_{M} \frac{D(\lambda-1)}{Q\left(\lambda^{n}-1\right)}+r C_{R} Q_{R a v g}+r C_{M P} E\left[Q_{P a v g}\right]+r C_{M D} E\left[Q_{D a v g}\right]+ \\
& C_{o} \frac{D}{f}+C_{I} D E[x]+C_{M} D
\end{aligned}
$$

\subsection{Customers' cost}

Ordering cost for $\mathrm{i}^{\text {th }}$ buyer per year is $A_{B i} \frac{n D(\lambda-1)}{Q\left(\lambda^{n}-1\right)}$

The $\mathrm{i}^{\text {th }}$ buyer receives batches of sizes $Q_{i}, \lambda Q_{i}, \ldots \lambda^{n-1} Q_{i}$. The average inventory for $\mathrm{i}^{\mathrm{th}}$ buyer per cycle is $\frac{Q^{2} D_{i}\left(\lambda^{2 n}-1\right)}{2 D^{2}\left(\lambda^{2}-1\right)}$.

Hence the inventory holding cost for $\mathrm{i}^{\text {th }}$ buyer per year is $r C_{B i} \frac{Q D_{i}\left(\lambda^{n}+1\right)}{2 D(\lambda+1)}$

Transportation cost for $\mathrm{i}^{\text {th }}$ buyer per year is $C_{T i} \frac{n D(\lambda-1)}{Q\left(\lambda^{n}-1\right)}$

Hence all customers' cost per year is

$T C_{B}=\frac{n D(\lambda-1)}{Q\left(\lambda^{n}-1\right)} \sum_{i=1}^{k}\left(A_{B i}+C_{T i}\right)+\frac{Q\left(\lambda^{n}+1\right)}{2 D(\lambda+1)} \sum_{i=1}^{k} r C_{B i} D_{i}$

Finally, the expected total cost function of the integrated model over the infinite planning horizon including expected manufacturers cost and customers' costs is as follows,

$T C=T C_{M}+T C_{B}$ 
For each case of the raw material orders, an updated total cost function is written independently. The total cost equations for Case 1 and Case 2 are indicated by $T C_{1}(Q, \lambda, n, m)$ and $T C_{2}(Q, \lambda, n, m)$, respectively.

\section{Solution Methodology}

The expected cost function has only four decision variables $Q, \lambda, n, m$.We can assume that $Q, \lambda$ are continuous variables, while both $n$ and $m$ are discrete variables ( $m, n$ take integer values).

Case 1: When $v=\{1,2, \ldots m\}$, the expected total relevant cost per year is given by

$$
T C_{1}(Q, \lambda, n, m)=\frac{D}{Q} \Omega+\frac{Q}{2} r \psi+D \phi
$$

where

$$
\begin{aligned}
\Omega= & \frac{(\lambda-1)}{\left(\lambda^{n}-1\right)}\left[\frac{A_{R}}{m}+A_{M}+n \sum_{i=1}^{k}\left(A_{B i}+C_{T i}\right)\right] \\
\psi= & \frac{\lambda^{n}-1}{\lambda-1}\left[C_{R}\left(\frac{m-1}{f}+\frac{D}{P f}\right)-C_{M P} \frac{D}{P}+\left(C_{M D}-C_{M P}\right) D\left(\frac{E[x]}{P}+\frac{E\left[x^{2}\right]}{P_{1}}\right)\right]+2 C_{M P} \frac{\lambda\left(\lambda^{n-1}-1\right)}{\lambda^{2}-1}+ \\
& 2 C_{M P} \frac{D}{P} E\left[\frac{1}{1-x}\right]+\frac{\lambda^{n}+1}{D(\lambda+1)} \sum_{i=1}^{k} C_{B i} D_{i} \\
\varphi= & \frac{C_{o}}{f}+C_{I} E[x]+C_{M}
\end{aligned}
$$

Case 2: When $v=\{1,1 / 2, \ldots, 1 / m\}$, the expected total relevant cost per year is given by

$$
T C_{2}(Q, \lambda, n, m)=\frac{D}{Q} \delta+\frac{Q}{2} r \Gamma+D \phi
$$

where

$$
\begin{aligned}
& \delta=\frac{(\lambda-1)}{\left(\lambda^{n}-1\right)}\left[m A_{R}+A_{M}+n \sum_{i=1}^{k}\left(A_{B i}+C_{T i}\right)\right] \\
& \Gamma=\frac{\lambda^{n}-1}{\lambda-1}\left[C_{R} \frac{D}{m P f}-C_{M P} \frac{D}{P}+\left(C_{M D}-C_{M P}\right) D\left(\frac{E[x]}{P}+\frac{E\left[x^{2}\right]}{P_{1}}\right)\right]+2 C_{M P} \frac{\lambda\left(\lambda^{n-1}-1\right)}{\lambda^{2}-1}+2 C_{M P} \frac{D}{P} E\left[\frac{1}{1-x}\right]+ \\
& \frac{\lambda^{n}+1}{D(\lambda+1)} \sum_{i=1}^{k} C_{B i} D_{i}
\end{aligned}
$$

The problem can be formulated by

$\min \operatorname{TC}(Q, \lambda, n, m)$

Subject to $1<\lambda<\frac{P E[1-x]}{D}$

$$
\begin{aligned}
& Q>0 \\
& n, m \in Z^{+}
\end{aligned}
$$

Here we first minimize expected total cost for the both cases (case 1 \& case 2) and then select the case which is able to give the lower expected total cost.

Proposition 1. For fixed $n, m$ and $\lambda, T C_{i}(Q, \lambda, n, m)$ is convex in $Q$. (where $=1,2$ )

\section{Proof.}

For fixed $\lambda, n, m$, taking first and second derivatives with respect to $Q$ gives:

Case 1:

$\frac{\partial T C_{1}}{\partial Q}=-\frac{D}{Q^{2}} \Omega+\frac{1}{2} r \psi, \quad \frac{\partial^{2} T C_{1}}{\partial Q^{2}}=\frac{2 D}{Q^{3}} \Omega>0$

Therefore, $T C_{1}(Q, \lambda, n, m)$ is convex on $Q$. 
Case 2:

$\frac{\partial T C_{2}}{\partial Q}=-\frac{D}{Q^{2}} \delta+\frac{1}{2} r \Gamma, \quad \frac{\partial^{2} T C_{1}}{\partial Q^{2}}=\frac{2 D}{Q^{3}} \delta>0$.

Therefore, $T C_{1}(Q, \lambda, n, m)$ is convex on $Q$. Hence the proposition follows.

Now, for optimality, setting $\frac{\partial T C_{i}}{\partial Q}=0$ yields,

Case 1:

$Q^{*}=\sqrt{\frac{2 D \Omega}{r \psi}}$.

Substituting $Q^{*}$ in Eq. (6), the expected total cost function becomes

$T C_{1}\left(Q^{*}, \lambda, n, m\right)=\sqrt{2 D r \psi \Omega}+D \varphi$.

Minimization of $T C_{1}\left(Q^{*}, \lambda, n, m\right)$ is equivalent to minimization of $\sqrt{2 \operatorname{Dr} \psi \Omega}$, which is equivalent to Minimization of $2 \operatorname{Dr} \psi \Omega$, thus,

$\min T C_{1}\left(Q^{*}, \lambda, n, m\right) \equiv \operatorname{Min} \sqrt{2 \operatorname{Dr} \psi \Omega} \equiv \operatorname{Min} 2 \operatorname{Dr} \psi \Omega$

Case 2:

Similar to Case 1's procedure, we obtain the following functions and relationship for Case 2:

$Q^{*}=\sqrt{\frac{2 D \delta}{r \Gamma}}$

$T C_{2}\left(Q^{*}, \lambda, n, m\right)=\sqrt{2 D r \Gamma \delta}+D \varphi$

and

$\min T C_{2}\left(Q^{*}, \lambda, n, m\right) \equiv \operatorname{Min} \sqrt{2 D r \Gamma \delta} \equiv \operatorname{Min} 2 \operatorname{Dr} \Gamma \delta$

Proposition 2. For fixed $m, T C_{i}\left(Q^{*}, n, m\right)$ is convex in $n$ when $\lambda=1$. (where $=1,2$ )

Proof: The proof of the proposition is straightforward and hence omitted.

Proposition 3. For fixed $m, T C_{i}\left(Q^{*}, n, m\right)$ is convex in $n$ when $\lambda=\frac{P E[1-x]}{D}(>1)$. (where $\left.=1,2\right)$

\section{Proof.}

Case 1:

Let $g(n)$ be the function of $T C_{1}\left(Q^{*}, n, m\right)$ subtracting terms which are independent of $n$ Thus,

$$
g(n)=\frac{(K+n L)}{\left(\lambda^{n}-1\right)}\left(\lambda^{n} S+T\right)
$$

where, $K=(\lambda-1)\left(\frac{A_{R}}{m}+A_{M}\right), L=(\lambda-1) \sum_{i=1}^{k}\left(A_{B i}+C_{T i}\right)$, 
$S=C_{R} \frac{1}{(\lambda-1)}\left(\frac{m-1}{f}+\frac{D}{P f}\right)+C_{M P}\left[\frac{2}{\lambda^{2}-1}-\frac{D}{P(\lambda-1)}-\frac{D}{(\lambda-1)}\left(\frac{E[x]}{P}+\frac{E\left[x^{2}\right]}{P_{1}}\right)\right]+C_{M D} \frac{D}{(\lambda-1)}\left(\frac{E[x]}{P}+\quad \frac{E\left[x^{2}\right]}{P_{1}}\right)+$ $\frac{1}{D(\lambda+1)} \sum_{i=1}^{k} C_{B i} D_{i}$,

$$
\begin{aligned}
T= & C_{M P}\left[2 \frac{D}{P} E\left[\frac{1}{1-x}\right]+\frac{D}{P(\lambda-1)}+\frac{D}{(\lambda-1)}\left(\frac{E[x]}{P}+\frac{E\left[x^{2}\right]}{P_{1}}\right)-\frac{2 \lambda}{\lambda^{2}-1}\right]-C_{R} \frac{1}{(\lambda-1)}\left(\frac{m-1}{f}+\frac{D}{P f}\right)- \\
& C_{M D} \frac{D}{(\lambda-1)}\left(\frac{E[x]}{P}+\frac{E\left[x^{2}\right]}{P_{1}}\right)+\frac{1}{D(\lambda+1)} \sum_{i=1}^{k} C_{B i} D_{i}
\end{aligned}
$$

To prove that $T C_{1}\left(Q^{*}, n, m\right)$ is convex in positive integral $n$, it is enough to show that $g(n)$ is convex in positive real $n$. We find that $g(n) \rightarrow \infty$ as $n \rightarrow \infty$ and $g(n) \rightarrow \infty$ as $n \rightarrow 0$ (As $S>0$ ). Also $g(n$ ) is continuous and finite between these two limits. Thus, it is convex if it has a single turning point in the interval $(0, \infty)$.

The numerator of $g^{\prime}(n)$ reduces to

$h(n)=L\left(A \lambda^{n}+B\right)\left(\lambda^{n}-1\right)-(S+T) \lambda^{n}(K+n L) \log (\lambda)$

and the denominator is positive for $n>0$. We therefore need to show that $h(n)$ has only one zero for positive $n . h(0)<0$ and $h(n) \rightarrow \infty$ as $n \rightarrow \infty$.

$$
h^{\prime}(n)=\lambda^{n} \log (\lambda)\left[2 L S \lambda^{n}-2 L S-(S+T)(K+n L) \log (\lambda)\right]
$$

$h^{\prime}(n)$ is also negative when $n=0$ and $h^{\prime}(n) \rightarrow \infty$ as $n \rightarrow \infty$. Thus $h^{\prime}(n)=0$ has a single solution $n^{*}$ (say).Therefore $h(n)$ is negative when $n=0$, decreases until $n=n^{*}$ and then as $n$ increases $h(n)$ increases indefinitely. Hence $h(n)$ has only one zero for positive real $\mathrm{n}$ and this completes the proof. Similar to Case 1's procedure we can prove that $T C_{2}\left(Q^{*}, n, m\right)$ is convex in positive integral $n$.

If $n^{\prime}$ and $n^{\prime \prime}$ be the optimal values of $n$ for $\lambda=1$ and $\frac{P E[1-x]}{D}$, then following the assumption of Hill (1997), the optimal value of $n$ for general $\lambda$ lies in $\left[n^{\prime}, n^{\prime \prime}\right]$

Proposition 4. For fixed $\lambda$ and $n, T C_{i}\left(Q^{*}, \lambda, n, m\right)$ is convex in $m$. (where $=1,2$ )

\section{Proof:}

\section{Case 1:}

Let $\theta_{1}(m)$ be the function of $T C_{1}\left(Q^{*}, \lambda, n, m\right)$ subtracting terms which are independent of $m$ Thus,

$$
\theta_{1}(m)=\left(\frac{\alpha}{m}+\beta\right)(m \gamma+\rho)
$$

where

$\alpha=A_{R} \frac{(\lambda-1)}{\left(\lambda^{n}-1\right)}, \quad \beta=n \frac{(\lambda-1)}{\left(\lambda^{n}-1\right)} \sum_{i=1}^{k}\left(A_{B i}+C_{T i}\right), \gamma=C_{R} \frac{\lambda^{n}-1}{\lambda-1}$ and

$\rho=\psi-m C_{R} \frac{\lambda^{n}-1}{\lambda-1}$

To prove that $T C_{1}\left(Q^{*}, \lambda, n, m\right)$ is convex in positive integral $m$, it is enough to show that $\theta_{1}(m)$ is convex in positive real .

$\frac{\partial \theta}{\partial m}=\beta \gamma-\alpha \rho \frac{1}{m^{2}}, \quad \frac{\partial^{2} \theta}{\partial m^{2}}=\alpha \rho \frac{1}{m^{3}}>0$

Therefore, $T C_{1}\left(Q^{*}, \lambda, n, m\right)$ is convex on $m$. 
Case 2:

Similar to Case 1's procedure, we obtain $\theta_{2}(m)$ be the function of $T C_{2}\left(Q^{*}, \lambda, n, m\right)$ subtracting terms which are independent of $m$.

Thus

$$
\theta_{2}(m)=\left(\frac{\eta}{m}+\sigma\right)(m \alpha+\beta),
$$

where

$\eta=C_{R} \frac{D\left(\lambda^{n}-1\right)}{f P(\lambda-1)}$ and $\sigma=\Gamma-C_{R} \frac{D\left(\lambda^{n}-1\right)}{m f P(\lambda-1)}$,

and

$\frac{\partial \theta}{\partial m}=\alpha \sigma-\frac{\beta \eta}{m^{2}}, \quad \frac{\partial^{2} \theta}{\partial m^{2}}=\beta \eta \frac{1}{m^{3}}>0$.

Therefore, $T C_{2}\left(Q^{*}, \lambda, n, m\right)$ is convex on $m$.

Proposition 5. The optimal value of $m^{*}$ must satisfy

$$
\begin{array}{ll}
m^{*}\left(m^{*}-1\right) \leq \frac{\alpha \rho}{\beta \gamma} \leq m^{*}\left(m^{*}+1\right) & (\text { For case } 1) \\
m^{*}\left(m^{*}-1\right) \leq \frac{\beta \eta}{\alpha \sigma} \leq m^{*}\left(m^{*}+1\right) & (\text { For case } 2)
\end{array}
$$

\section{Proof:}

Case 1: We shall first assume $\lambda, n$ is given and by considering $m^{*}$ as the optimal value of $m$, according to convexity of $T C_{1}(Q, \lambda, n, m)$ on $m, m^{*}$ will satisfy

$\theta\left(\lambda, n, m^{*}\right) \leq \theta\left(\lambda, n, m^{*}-1\right), \theta\left(\lambda, n, m^{*}\right) \leq \theta\left(\lambda, n, m^{*}+1\right)$

From Eq. (18), we obtain $m^{*}\left(m^{*}-1\right) \leq \frac{\alpha \rho}{\beta \gamma} \leq m^{*}\left(m^{*}+1\right)$

Case 2: Similar to Case 1's procedure, we obtain $m^{*}\left(m^{*}-1\right) \leq \frac{\beta \eta}{\alpha \sigma} \leq m^{*}\left(m^{*}+1\right)$

This completes the proof.

Algorithmic procedure is developed as follows to obtain the optimal solution for $(Q, \lambda, n, m)$ (this study adopted by Hill (1997) and Giri and Sharma (2014) to determine the optimal value of $Q, \lambda, n)$ ).

\section{Algorithm 1}

step 1 Substitute optimal value of $Q^{*}$ obtained from Eq. (8) into Eq. (6) for case 1, Eq. (11) into Eq. (7) for case 2

step 2 Determine the upper bound $n^{\prime \prime}$ of $n$ for $\lambda=\frac{P E[1-x]}{D}$ using algorithm 2

step 3 Initialize $n_{1}=1$

step $4 \quad$ (i) For each $\lambda \in\left[1, \frac{P E[1-x]}{D}\right]$, obtain the associate optimal value $m_{\lambda}^{*}$ using the inequality Eq. (17) for case 1, Eq. (18) for case 2

(ii) Find $T C_{1}\left(\lambda_{j}^{*}, n_{j}, m_{\lambda_{j}^{*}}^{*}\right)=\operatorname{Min}_{\lambda \in\left[1, \frac{P E[1-x]}{D}\right]} T C_{1}\left(\lambda, n_{j}, m_{\lambda}^{*}\right)$

step 5 If $n_{j}=n^{\prime \prime}$ then go to step 6 otherwise set $n_{j+1}=n_{j}+1$ and go to step 4 to get 


$$
T C_{1}\left(\lambda_{j+1}^{*}, n_{j+1}, m_{\lambda_{j+1}^{*}}^{*}\right) \text {. }
$$

Step 6 Find $T C_{1}\left(\lambda^{*}, n^{*}, m^{*}\right)=\min _{j} T C_{1}\left(\lambda_{j}^{*}, n_{j}, m_{\lambda_{j}^{*}}^{*}\right)$ and compute the corresponding $Q^{*}\left(\lambda^{*}, n^{*}, m^{*}\right)$ from Eq. (10), then $\left(Q^{*}, \lambda^{*}, n^{*}, m^{*}\right)$ is the optimal solution and $T C_{1}\left(Q^{*}, \lambda^{*}, n^{*}, m^{*}\right)$ is the minimum expected total cost for case 1 .

To determine the upper bound $n^{\prime \prime}$ of $n$ for $\lambda=\frac{P E[1-x]}{D}$ we use the following algorithm

\section{Algorithm 2}

step 1 Substitute optimal value of $Q^{*}$ obtained from Eq. (8) into Eq. (6) for case 1

step 2 Initialize $=1, \lambda=\frac{P E[1-x]}{D}$ and $T C_{1}\left(0, m_{0}\right)=\infty$.

step 3 Determine the associate optimal value $m_{n}$ using the inequality Eq. (17) for case 1 and compute the corresponding $T C_{1}\left(n, m_{n}\right)$.

step 4 If $T C_{1}\left(n, m_{n}\right)<T C_{1}\left(n-1, m_{n-1}\right)$ then Set $n=n+1$ and go to step 2 to get $T C_{1}\left(n+1, m_{n+1}\right)$ otherwise go to step 5

step 5 Set $n-1=n^{\prime \prime}$.

Similar to the case 1, using the algorithm 1 we evaluate the optimal solution for the case 2 and then select the case which is able to give the lower expected total cost.

\section{Equal-sized Shipments}

For the equal-sized shipments $(\lambda=1)$ from manufacturer to buyers the expected total cost function for both cases (using L'Hospital's Rule) reduces to

For Case 1:

$$
\begin{aligned}
& T C_{1}=\frac{D}{Q}\left[\frac{1}{n}\left(\frac{A_{R}}{m}+A_{M}\right)+\sum_{i=1}^{k}\left(A_{B i}+C_{T i}\right)\right]+\frac{Q}{2} r\left[n C_{R}\left(\frac{m-1}{f}+\frac{D}{f P}\right)+C_{M P}\left[n\left(1-\frac{D}{P}\right)+\right.\right. \\
& \left.\left.\frac{2 D}{P} E\left[\frac{1}{1-x}\right]-1\right]+n\left(C_{M D}-C_{M P}\right) D\left(\frac{E[x]}{P}+\frac{E\left[x^{2}\right]}{P_{1}}\right)+\frac{1}{D} \sum_{i=1}^{k} C_{B i} D_{i}\right]+D\left[\frac{C_{o}}{f}+C_{I} E[x]+C_{M}\right]
\end{aligned}
$$

For Case 2:

$$
\begin{aligned}
T C_{2}= & \frac{D}{Q}\left[\frac{1}{n}\left(m A_{R}+A_{M}\right)+\sum_{i=1}^{k}\left(A_{B i}+C_{T i}\right)\right]+\frac{Q}{2} r\left[n C_{R} \frac{D}{m f P}+C_{M P}\left[n\left(1-\frac{D}{P}\right)+\right.\right. \\
& \left.\left.\frac{2 D}{P} E\left[\frac{1}{1-x}\right]-1\right]+n\left(C_{M D}-C_{M P}\right) D\left(\frac{E[x]}{P}+\frac{E\left[x^{2}\right]}{P_{1}}\right)+\frac{1}{D} \sum_{i=1}^{k} C_{B i} D_{i}\right]+ \\
& D\left[\frac{C_{o}}{f}+C_{I} E[x]+C_{M}\right]
\end{aligned}
$$

\section{Numerical Examples}

Let us consider a numerical example of supplying an item to 5 buyers by a manufacturer. The data of buyers are given in Table 1. Manufacturer's production rate is $P=31700$ and total demand $D=$ $\sum_{i=1}^{k} D_{i}=12600$. The defective rate $x$ is uniformly distributed with probability density function:

$f(x)=\left\{\begin{array}{rr}\frac{1}{0.3} & \text { if } 0 \leq x \leq 0.3 \\ 0 & \text { otherwise }\end{array}\right.$ 


\section{Table 1}

Data for a single-manufacturer 5-buyer problem

\begin{tabular}{rrrrr}
\hline $\mathbf{i}^{\text {th }}$ Buyer & $\boldsymbol{A}_{\boldsymbol{B} \boldsymbol{i}}$ & $\boldsymbol{D}_{\boldsymbol{i}}$ & $\boldsymbol{C}_{\boldsymbol{T} \boldsymbol{i}}$ & $\boldsymbol{C}_{\boldsymbol{B} \boldsymbol{i}}$ \\
\hline $\mathbf{1}$ & 11 & 3000 & 15 & 44 \\
$\mathbf{2}$ & 10.5 & 2300 & 10 & 46 \\
$\mathbf{3}$ & 12 & 1750 & 18 & 39 \\
$\mathbf{4}$ & 9.5 & 2900 & 15 & 47 \\
$\mathbf{5}$ & 8 & 2650 & 15 & 43 \\
\hline
\end{tabular}

All defective items produced are considered to be repairable and reworked at a rate of $P_{1}=33000$. The other parameters are: $r=0.2, A_{R}=100, A_{M}=750, C_{R}=10, C_{M P}=24, C_{M D}=15$,

$C_{I}=8, f=0.8, C_{o}=20, C_{M}=18$. Based on the above numerical data and using the algorithm 1 (for unequal shipments), we obtain the optimal results as given in Table 2.

\section{Table 2}

Optimal results for unequal shipment

\begin{tabular}{ccccc}
\hline Case & $\boldsymbol{n}$ & $\boldsymbol{\lambda}$ & $\boldsymbol{m}$ & $\boldsymbol{T C}$ \\
\hline $\mathbf{1}$ & 2 & 1.761111 & 1 & 570924.7963 \\
$\mathbf{2}$ & 2 & 1.761111 & 1 & 570924.7963 \\
$\mathbf{1}$ & 3 & 1.645868 & 1 & 570410.4626 \\
$\mathbf{2}$ & 3 & 1.645868 & $1 / 2$ & 570348.8303 \\
$\mathbf{1}$ & 4 & 1.437453 & 1 & 570394.8257 \\
$\mathbf{2}$ & $\mathbf{4}$ & $\mathbf{1 . 4 3 7 4 5 3}$ & $\mathbf{1} / \mathbf{2}$ & $\mathbf{5 7 0 2 2 2 . 4 7 8 9}$ \\
$\mathbf{1}$ & 5 & 1.332380 & $1 / 2$ & 570563.1776 \\
$\mathbf{2}$ & 5 & 1.332380 & 1 & 570304.3729 \\
$\mathbf{1}$ & 6 & 1.268477 & $1 / 2$ & 570817.6924 \\
$\mathbf{2}$ & 6 & 1.268477 & 1 & 570486.6199 \\
$\mathbf{1}$ & 7 & 1.225359 & $1 / 2$ & 571116.2496 \\
$\mathbf{2}$ & 7 & 1.225359 & & 570722.2437 \\
\hline
\end{tabular}

Fig 2 shows that expected total cost per year for the both cases 1 and 2 is strictly convex function on $n$. As a result, we are sure that the minimum obtained from the proposed algorithm is indeed the global optimum solution. From Table 2, we observe that optimal solution is obtained in case 2, when $n^{*}=$ $4, v^{*}=1 / 2, \lambda^{*}=1.437453$ and the corresponding minimum expected total cost per year $T C^{*}=$ $T C_{2}^{*}=570222.4789$, when $\lambda=1$ we obtain $n^{*}=4, v^{*}=1 / 2$ and the corresponding minimum expected total cost per year $T C_{2}^{*}=570833.5676$.

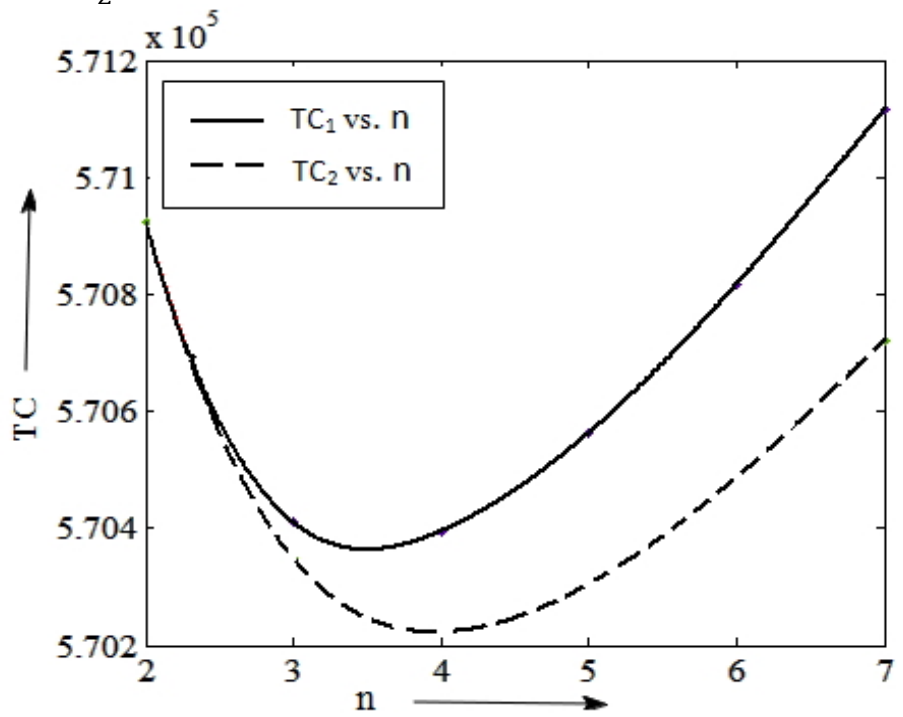

Fig. 2. The expected total profit for various value of $\mathrm{n}$ for Cases 1 and 2 
Table 3

A comparative study of the results for a single manufacturer 5-buyer problem

\begin{tabular}{ccc}
\hline Component & $\begin{array}{c}\text { Model : I } \\
\text { Unequal sized shipment to buyer }\end{array}$ & $\begin{array}{c}\text { Model : II } \\
\text { Equal sized shipment to buyer }\end{array}$ \\
\hline $\boldsymbol{Q}_{\boldsymbol{R}}, \boldsymbol{v}$ & $1712.049,1 / 2$ & $1636.856,1 / 2$ \\
$\boldsymbol{Q}_{\boldsymbol{M}}, \boldsymbol{n}$ & $2739.278,4$ & $2618.968,4$ \\
$\boldsymbol{S}_{\boldsymbol{i}}$ & $366.513,526.845,757.315$, & $654.742,654.742,654.742,654.742$ \\
& 1088.605 & \\
$\boldsymbol{T} \boldsymbol{C}_{\boldsymbol{M}}$ & 564442.6855 & 565556.5461 \\
$\boldsymbol{T} \boldsymbol{C}_{\boldsymbol{B} \boldsymbol{i}}$ & $1308.4619,1042.5075,981.1632$, & $1186.2700,944.2820,931.9785$, \\
& $1307.9041,1139.7567$ & $1179.7481,1034.7429$ \\
$\boldsymbol{T C}$ & 570222.4789 & 570833.5676 \\
\hline
\end{tabular}

A comparative study of the results of the Model I and Model II is given in Table 3. The cost reduction of Model I over Model II is about 11\%. Observe that the inventory cost of the manufacturer obtained in Model II is about 1.002 times higher than that of obtained in Model I but the total cost for each buyer in Model I is higher than the corresponding cost in Model II, so the cost reduction by Model I over Model II is mainly due to cost reduction in the cost of the manufacturer.

Table 4

Optimal results for different $A_{R}$

\begin{tabular}{cccc}
\hline $\boldsymbol{A}_{\boldsymbol{R}}$ & $\boldsymbol{v}^{*}$ & $\boldsymbol{Q}_{\boldsymbol{R}}^{*}$ & $\boldsymbol{T C}^{*}$ \\
\hline $\mathbf{5 0}$ & $1 / 2$ & 1651.789 & 569754.2638 \\
$\mathbf{1 0 0 0}$ & 1 & 4309.510 & 574243.3165 \\
$\mathbf{1 0 0 0 0}$ & 3 & 12894.301 & 591389.8670 \\
\hline
\end{tabular}

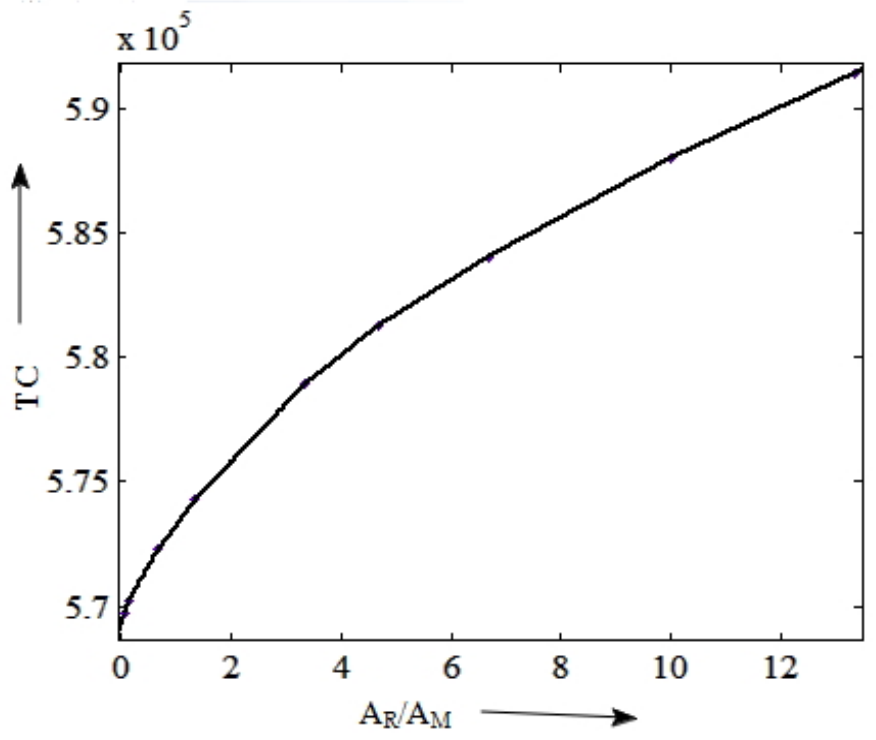

Fig. 3. Impact of AR/AM on total cost

$A_{R}$ plays a significant role in the optimal solution. Table 4 shows how the solution changes due to change of the value of $A_{R}$ from $\$ 50$ /order to $\$ 10000$ /order while all other parameters remain unchanged. The increase in the ordering cost causes the increase of the optimal order size of the raw material $Q_{R}$ to reduce the number of raw material orders. The change of $A_{R}$ is expressed using the ratio of raw material ordering cost versus set up cost $A_{R} / A_{M}$ for the simplicity of expression. Fig. 3 shows the impact of the ratio increase, the increase of raw material ordering cost, on the expected total cost of the integrated inventory system. 


\section{Conclusion}

In this paper we have developed an integrated production-delivery inventory model with imperfect production process in a supply chain consisting of a single manufacturer and multi-buyer. We have considered all types of costs such as fixed, material and holding costs at each stages in the supply chain: raw material procurement from supplier, manufacturing and remanufacturing at manufacturer's facility and purchasing by customers. The effective algorithms have been developed to obtain an optimal set of lot sizes and numbers of shipments which will minimize the expected total cost. We have observed that the model I when successive shipments to buyer are increasing by a constant factor gives improved result than the Model II under equal shipment policy.

\section{Appendix A.}

Case 1: In this case $v=\{1,2, \ldots, m\}$ i.e. each lot size of ordered raw material will meet the demand of $m$ (say) production run. Therefore, for this policy $Q_{R}=m Q_{M} / f$ and the cycle length is $m Q_{M} / D$. From Fig. 1, the stock holding area for raw material is

$$
\frac{m Q_{M}^{2}}{2 f P}+\frac{Q_{M}^{2}}{f D}[(m-1)+(m-2)+. .+1]
$$

Thus, the average inventory for raw material per year $\left(Q_{\text {Ravg }}\right)$ is (A.1) divided by cycle length.

Therefore

$$
Q_{\text {Ravg }}=\frac{Q\left(\lambda^{n}-1\right)}{2 f(\lambda-1)}\left(\frac{D}{P}+m-1\right)
$$

Case 2: In this case $v=\{1,1 / 2, \ldots, 1 / m\}$ i.e. manufacturer needs to replenish raw material $m$ (say) times for every production run. Therefore, for this policy $Q_{R}=Q_{M} / m f$ and the cycle length is $Q_{M} / D$. From Fig. 2, the stock holding area for raw material is

$$
m \frac{Q_{M}^{2}}{2 m^{2} f P}
$$

Thus, the average inventory for raw material per year $\left(Q_{R a v g}\right)$ is (A.3) divided by cycle length. Hence,

$$
Q_{\text {Ravg }}=\frac{Q\left(\lambda^{n}-1\right)}{2 f(\lambda-1)}\left(\frac{D}{m P}\right)
$$

\section{Appendix B}

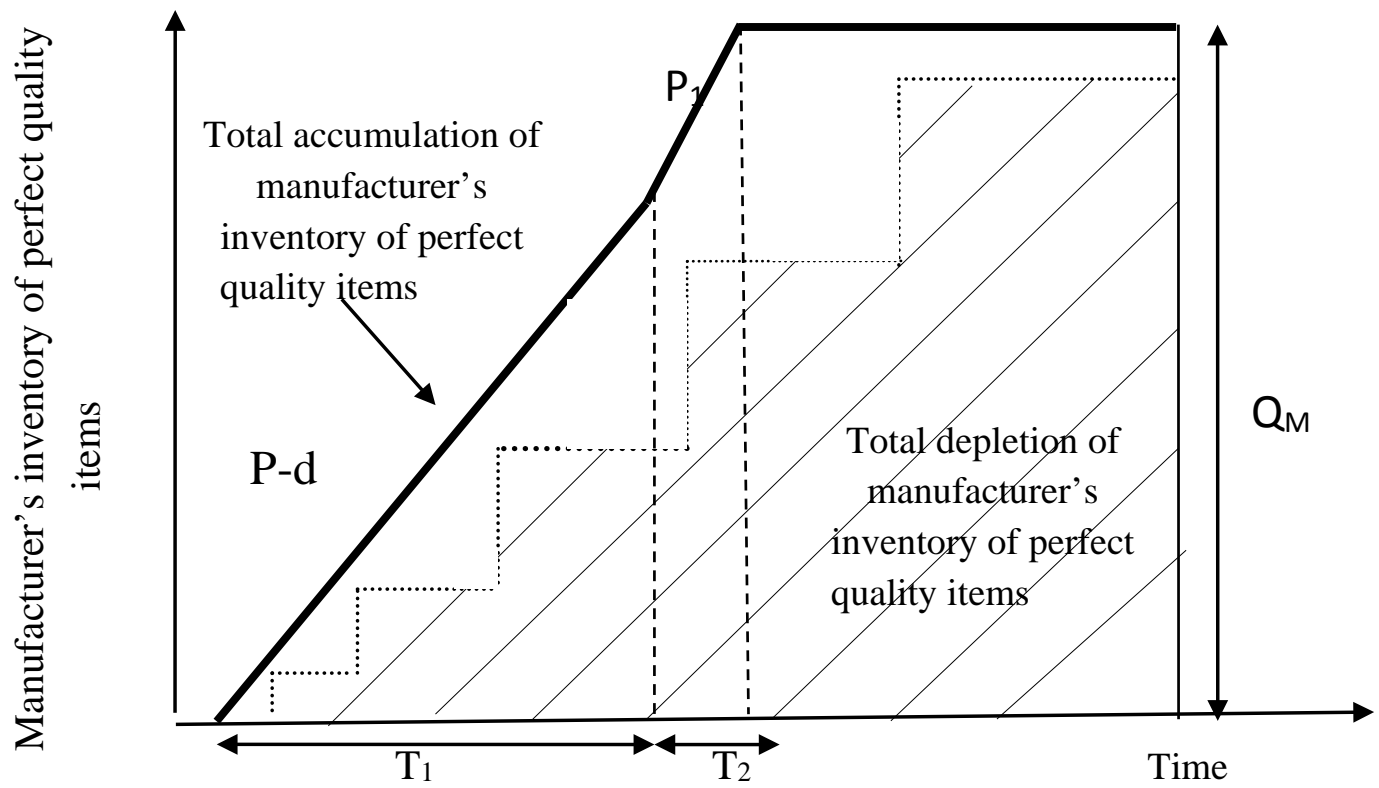

Fig. 4. Accumulation and depletion of manufacturer's inventory of perfect quality items 
From Fig 4, the stock holding area for the manufacturer finished item of perfect quality is as follows,

$=$ bold area - shaded

$$
\begin{aligned}
& =\frac{1}{2} \frac{Q_{M}}{P}(1-x) Q_{M}+\frac{x^{2} Q_{M}^{2}}{2 P_{1}}+(1-x) Q_{M}^{2} \frac{x}{P_{1}}+Q_{M}\left[\frac{Q}{P(1-x)}+\frac{Q}{D}+\frac{\lambda Q}{D}+. .+\frac{\lambda^{n-2} Q}{D}-\frac{Q_{M}}{P}-\frac{x Q_{M}}{P_{1}}\right]- \\
& {\left[\frac{Q^{2}}{D}+(Q+\lambda Q) \frac{\lambda Q}{D}+\cdots+\left(Q+\lambda Q+. .+\lambda^{n-2} Q\right) \frac{\lambda^{n-2} Q}{D}\right]} \\
& =\frac{1}{2} \frac{Q_{M}}{D}\left[\frac{2 D Q}{P(1-x)}+Q \frac{2 \lambda\left(\lambda^{n-1}-1\right)}{\lambda^{2}-1}-Q \frac{\lambda^{n}-1}{\lambda-1}\left[\frac{D}{P}+D\left(\frac{x}{P}+\frac{x^{2}}{P_{1}}\right)\right]\right]
\end{aligned}
$$

The cycle length is $Q_{M} / D$ year. Thus, the average inventory for manufacturer finished item of perfect quality per year $\left(Q_{P a v g}\right)$ is (B.1) divided by the cycle length. Therefore

$$
Q_{\text {Pavg }}=\frac{Q}{2}\left[\frac{2 D}{P(1-x)}+\frac{2 \lambda\left(\lambda^{n-1}-1\right)}{\lambda^{2}-1}-\frac{\lambda^{n}-1}{\lambda-1}\left[\frac{D}{P}+D\left(\frac{x}{P}+\frac{x^{2}}{P_{1}}\right)\right]\right]
$$

\section{References}

Banerjee, A. (1986). A joint economic lot size model for purchaser and vendor. Decision Sciences, 17(3), 292-312.

Giri, B. C. \& Chakraborty, A. (2011). Supply chain coordination for a deteriorating product under stockdependent consumption rate and unreliable production process. International Journal of Industrial Engineering Computations, 2, 263-272.

Giri, B.C. \& Sharma, S. (2014). Lot sizing and unequal-sized shipment policy for an integrated production-inventory system. International Journal of System Science, 45(5), 888-901.

Golhar, D. Y., \& Sarker, B. R. (1992). Economic manufacturing quantity in a just-in time delivery system. International Journal of Production Research, 30(5), 961-972.

Goyal, S.K. (1977). Determination of optimal production quantity for a two-stage production system. Operational Research Quarterly, 28, 865-870.

Goyal, S.K., \& Gupta, Y.P. (1989). Integrated inventory models: the buyer-vendor coordination. European Journal of Operational Research, 41, 261-269.

Goyal, S. K. (1995). A one-vendor multi-buyer integrated inventory model: A comment. European Journal of Operational Research, 82(1), 209-210.

Goyal, S. K., \& Nebebe, F. (2000). Determination or economic production-shipment policy for a singlevendor single buyer system. European Journal of Operational Research, 121(1), 175-178.

Haji R., Haji A., Sajadifar M., \& Zolfaghari S. (2008). Lot sizing with non-zero setup times for rework. Journal of Systems Science and Systems Engineering, 17(2), 230-240.

Hayek, P. A., \& Salameh, M. K. (2001). Production lot sizing with the reworking of imperfect quality item produced. Production Planning \& Control: The Management of Operations, 12(6), 584-590.

Hill, R. M. (1997). The single-vendor single-buyer integrated production-inventory model with a generalized policy. European Journal of Operational Research, 97(3),493-499.

Hill, R. M. (1999). The optimal production and shipment policy for the single-vendor single-buyer integrated production-inventory problem. International Journal of Production Research, 37(11), 2463-2475.

Hoque, M. (2008). Synchronizaton in the single-vendor multi-buyer integrated inventory supply chain. European Journal of Operational Research, 188(3), 811-825.

Hsu, J.T. \& Hsu, L.F. (2012). An integrated single-vendor single-buyer production-inventory model for items with imperfect quality and inspection errors. International Journal of Industrial Engineering Computations, 3,703-720.

Jamal, A. M. M., \& Sarker, B. R. (1993). An optimal batch size for a production system operating under a just-in-time delivery system. International Journal of Production Economics, 32(2), 255-260. 
Jamal, A. M. M, Sarker B. R., \& Mondal, S. (2004). Optimal manufacturing batch size with rework process at a single-stage production system. Computers \& Industrial Engineering, 47, 77-89.

Joglekar, P.N., \& Tharthare, S. (1990). Individually responsible and rational decision approach to economic lot sizes for one vendor and many purchasers. Decision Sciences, 21, 450-492.

Lee, H.H., Chandra, M. J., \& Deleveaux, V. J. (1997). Optimal batch size and investment in multistage production systems with scrap. Production Planning and Control, 8(6), 586-596.

Lee,W. (2005). A joint economic lot size model for raw material ordering, manufacturing setup, and finished goods delivery. Omega-International Journal of Management Science, 33(2), 163-174.

Lu, L. (1995). A one-vendor multi-buyer integrated inventory model. European Journal of Operational Research, 81, 312-323.

Sarker, B. R., \& Parija, G. R. (1994). An optimal batch size for a production system operating under a fixed-quantity, periodic delivery policy. Journal of the Operational Research Society, 45(8), 891-900.

Viswanathan, S., \& Piplani, R. (2001).Coordinating supply chain inventories through common replenishment epochs. European Journal of Operational Research, 129, 277-286. 